\title{
pH-responsive hydrogel membranes based on modified chitosan: water transport and kinetics of swelling
}

\author{
Jadwiga Ostrowska-Czubenko $^{1} \cdot$ Magdalena Gierszewska $^{1} \cdot$ Milena Pieróg $^{1}$
}

Received: 27 February 2015 / Accepted: 18 June 2015 / Published online: 19 July 2015

(C) The Author(s) 2015. This article is published with open access at Springerlink.com

\begin{abstract}
H}-$-responsive membranes prepared by treating chitosan $(\mathrm{Ch})$ with glutaraldehyde (GA) or with GA and sulfuric acid (SA) were studied. The structure and properties of the membranes were characterized by Fourier transform infrared (FTIR) spectroscopy, wide-angle X-ray diffraction (WAXD), scanning electron microscopy (SEM), atomic force microscopy (AFM), thermogravimetric analysis (TGA), differential scanning calorimetry (DSC) and elemental analysis. The effect of the cross-linking process both on the dynamic swelling behaviour of the hydrogel membranes and on the mechanism of water transport through those membranes was investigated in buffer solutions of different $\mathrm{pH}$ (1.2-9.5). The mechanism of water transport through the hydrogel chitosan membranes was affected by membrane composition and $\mathrm{pH}$ of the swelling medium. Non-cross-linked $\mathrm{Ch}$ membrane showed a non-Fickian swelling behaviour in the $\mathrm{pH}$ range 6.5-9.5. Chitosan membrane cross-linked with $\mathrm{GA}(\mathrm{Ch} / \mathrm{GA})$ showed less-Fickian or Fickian swelling behaviour in all buffer solutions. In the case of chitosan membrane cross-linked with GA and SA (Ch/GA/SA), at low $\mathrm{pH}$ (lower than the $\mathrm{p} K_{\mathrm{a}}$ of the hydrogel) the water transport was controlled more by polymer relaxation than by penetrant diffusion. The experimental data clearly suggested that the swelling process in all buffer solutions obeyed second-order kinetics. Values of an apparent swelling rate constant for $\mathrm{Ch} /$ GA and $\mathrm{Ch} / \mathrm{GA} / \mathrm{SA}$ membranes were of the same order of magnitude for acidic and neutral swelling media but they increased for alkaline solutions.
\end{abstract}

Jadwiga Ostrowska-Czubenko

jocz@chem.uni.torun.pl

1 Faculty of Chemistry, Nicolaus Copernicus University in Torun, Gagarina St. 7, 87-100 Toruń, Poland
Keywords Membranes · Chitosan cross-linking · pH-responsive polymers · Water transport · Swelling kinetics

\section{Introduction}

In recent years, stimuli-responsive membranes have received much attention owing to their many potential applications in drug delivery systems, chemical separations, water treatment, chemical sensing, bioreactors, etc. Stimuli-responsive membranes change their physical properties in response to changes in environmental conditions, such as $\mathrm{pH}$, solution ionic strength, temperature, concentration of specific chemical species, electric and magnetic field [1-3]. Changes in the physical properties of the membrane in response to changed environmental conditions can lead to changes in the mass transfer and interfacial properties of the membrane. Among the stimuli that can be used to control the response of the system, temperature and $\mathrm{pH}$-responsive factors have drawn much attention. In general, responsive membranes are formed from stimuli-sensitive materials (polymers or copolymers) or by modification of existing membranes by various chemical/physical processes to incorporate stimuli-responsive polymers [1,2]. An example of a $\mathrm{pH}$-sensitive polymer is the natural polymer chitosan.

Chitosan $(\mathrm{Ch})$ is a linear copolymer of $\beta$ - $(1 \rightarrow 4)$-linked 2acetamido-2-deoxy- $\beta$-D-glucopyranose and 2-amino-2deoxy- $\beta$-D-glucopyranose (Fig. 1). It is obtained by deacetylation of chitin, a polymer widely distributed in nature, including exoskeletons of crustaceans, insects and certain fungi [4]. Owing to chitosan's excellent properties, such as biocompatibility, biodegradability, hydrophilicity, non-toxicity, cationicity, ease of modification, ability to form of gels, films, nanoparticles, microparticles and beads, affinity to metals, protein and dyes, etc., it has found practical applications in medicine and pharmacy, as a food additive, antimicrobial 


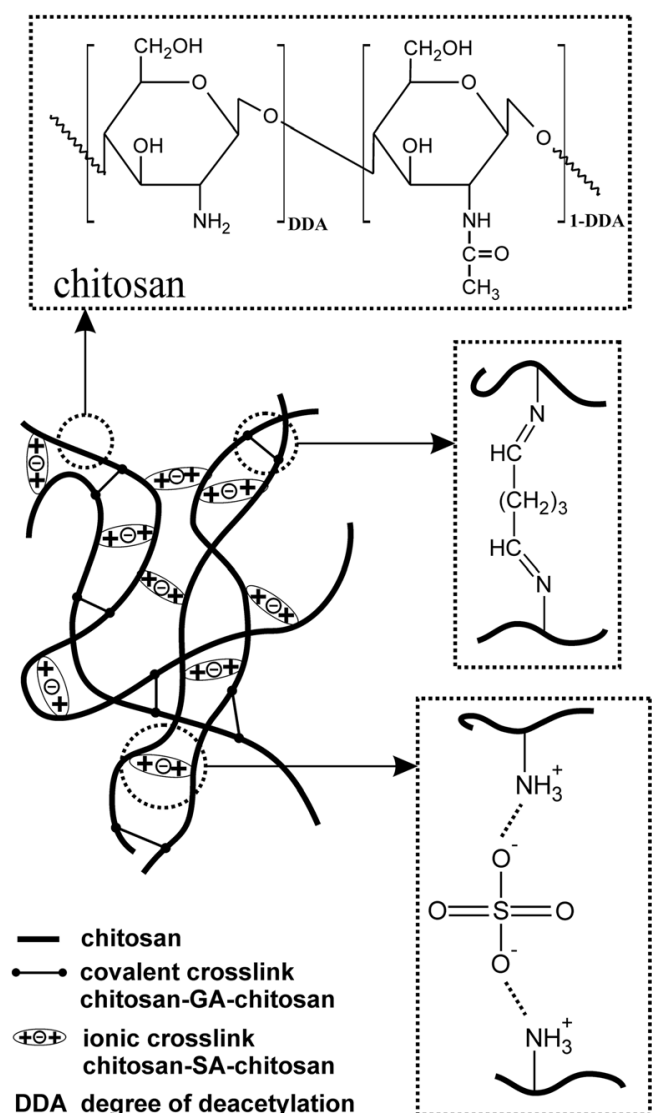

Fig. 1 Schematic representation of chemical structure of non-crosslinked and cross-linked chitosan membranes

agent, in environmental remediation and in different industrial areas. Moreover, chitosan is a polymeric material with high hydrophilicity, favourable permselectivity of water, excellent chemical-resistant properties [4]. This desirable combination of properties of $\mathrm{Ch}$ and its availability makes this polymer an attractive material for preparation of membranes for various uses, namely for pervaporation, separation of gaseous mixtures, separation and recovery of pollutants from wastewater, adsorption/separation of amino acids and proteins and for drug delivery [5].

The main disadvantage of hydrogels, including chitosan hydrogel membranes, is their poor mechanical properties after swelling. To improve mechanical and chemical resistance of chitosan membranes many studies have focused on the modification of chitosan by different methods, including blending, multilayer casting, addition of inorganic reinforcements and cross-linking [5]. In this work we have used the cross-linking reaction of chitosan with glutaraldehyde (GA) and sulfuric acid (SA) to obtain doubly cross-linked chitosan hydrogel $(\mathrm{Ch} / \mathrm{GA} / \mathrm{SA})$ membrane having improved mechanical and chemical stability in acidic media and designed for industrial applications.

The purpose of this work was to characterize both the swelling kinetics and the mechanism of water diffusion into non-cross-linked and cross-linked chitosan membranes in buffer solutions of different $\mathrm{pH}$. Swelling characteristics and diffusional behaviour of hydrogels are the key to their usefulness in biomedical, pharmaceutical and industrial applications. For example, knowledge about swelling kinetics is important for designing controlled-released devices for drugs and agriculture pesticides based on swellable polymer matrices and for predicting the release rates of the active ingredients.

\section{Experimental}

\section{Materials}

Commercially available chitosan from crab shells of medium molecular weight and glutaraldehyde ( $25 \mathrm{wt} \%$ solution in water) of analytical grade were purchased from Sigma-Aldrich (Germany). Acetic acid, sulfuric acid and sodium hydroxide were analytical grade and were purchased from POCh (Poland). Reagents for preparation of buffer solutions of constant ionic strength (hydrochloric acid, acetic acid, sodium acetate, sodium chloride) and Tris buffer of analytical grade were purchased from POCh (Poland) or Sigma-Aldrich (Germany). Potassium bromide for spectroscopy was purchased from Merck (Germany).

\section{Chitosan characterization}

The degree of deacetylation (DDA) of chitosan determined by potentiometric titration was $75.72 \pm 3.82 \%$. The viscosity average molecular weight $\left(M_{\mathrm{v}}\right)$ of chitosan solutions determined by viscosity analysis was $730 \pm 16 \mathrm{kDa}$. The details of DDA and $M_{\mathrm{v}}$ determinations are described elsewhere [6].

\section{Preparation of chitosan membranes}

Non-cross-linked $(\mathrm{Ch})$ and GA-cross-linked chitosan $(\mathrm{Ch} /$ GA) membranes were prepared by solution casting and solvent evaporation technique. To obtain non-cross-linked chitosan membranes $1 \%(\mathrm{w} / \mathrm{v})$ chitosan solution in $2 \%(\mathrm{w} / \mathrm{v})$ acetic acid was prepared. The polymer solution was then filtered, left overnight, degassed, cast as a film on a clean glass plate and evaporated to dryness at room temperature. The resultant membrane was removed from the glass plate, immersed in $2 \mathrm{M}$ sodium hydroxide solution for $5 \mathrm{~min}$ to remove the residual acid, thoroughly washed with deionised water and dried at $37^{\circ} \mathrm{C}$. To obtain GA-cross-linked chitosan membrane the $0.25 \mathrm{wt} \%$ glutaraldehyde solution was added dropwise over $5 \mathrm{~min}$ to chitosan solution under gentle stirring and the mixture was left for about $1 \mathrm{~h}$ to prevent any air bubble formation. Then the solution was cast as a film on a clean glass plate and evaporated to dryness at $37{ }^{\circ} \mathrm{C}$. The content of 
glutaraldehyde in the casting solution was $2.5 \mathrm{wt} \%$. Finally, the prepared membrane was washed repeatedly with doubly distilled water, immersed in $2 \mathrm{M}$ sodium hydroxide solution for $5 \mathrm{~min}$, washed repeatedly with water and dried at $37^{\circ} \mathrm{C}$. Doubly cross-linked chitosan membrane, i.e. chitosan membrane cross-linked with glutaraldehyde and sulfuric acid $(\mathrm{Ch} /$ $\mathrm{GA} / \mathrm{SA}$ ), was prepared by immersing pure $\mathrm{Ch} / \mathrm{GA}$ membrane in $0.5 \mathrm{M}$ sulfuric acid solution for $24 \mathrm{~h}$, washing thoroughly with doubly distilled water and drying. Before spectral and swelling measurements, non-cross-linked and cross-linked membranes were thoroughly dried under vacuum at $60{ }^{\circ} \mathrm{C}$ for $24 \mathrm{~h}$.

\section{Chitosan membrane characterization}

All membranes were characterized by FTIR spectroscopy, wide-angle X-ray diffraction (WAXD), scanning electron microscopy (SEM), atomic force microscopy (AFM), thermogravimetric analysis (TGA), differential scanning calorimetry (DSC) and elemental analysis.

FTIR spectra of non-cross-linked and cross-linked membranes in $\mathrm{KBr}$ disc form were recorded on a Perkin-Elmer 2000 FTIR spectrophotometer from 4000 to $400 \mathrm{~cm}^{-1}$ with a resolution $4 \mathrm{~cm}^{-1}$ and 100 scans. The polymer samples were ground into a fine powder using liquid nitrogen and thoroughly dried under vacuum at $60{ }^{\circ} \mathrm{C}$ before milling with anhydrous $\mathrm{KBr}$.

A Philips X-Pert Pro Systems X-ray diffractometer was used to study the solid-state morphology of the non-crosslinked and cross-linked chitosan membranes. X-ray diffraction was performed on powdered samples by exposing them to $\mathrm{CuK}_{\alpha}$ radiation and scanning from $2 \theta=4^{\circ}$ to $40^{\circ}$ with a step size of $0.02^{\circ}$.

TGA was carried out using an SDT 2960 Simultaneous TGA-DTA Thermal Analyzer System (TA Instruments, USA). All measurements were performed with polymer samples (about $5 \mathrm{mg}$ ) in aluminium pans under a dynamic nitrogen atmosphere, in the temperature range from room temperature to $500{ }^{\circ} \mathrm{C}$, at a scanning rate of $10{ }^{\circ} \mathrm{C} / \mathrm{min}$ and gas flow of $100 \mathrm{~mL} / \mathrm{min}$. For each degradation step the temperature at which the degradation starts, temperature at maximum process rate $\left(T_{\max }\right)$, temperature at which the degradation is finished and percentage weight loss ( $\mathrm{wt} \%$ ) were calculated from DTG curves.

DSC analysis was performed with a differential scanning calorimeter (Polymer Laboratories Ltd., Epsom, UK). Thoroughly dried membrane samples (about $15 \mathrm{mg}$ ) were weighed in an aluminium pan designed for volatile samples and sealed. They were heated from room temperature to $400{ }^{\circ} \mathrm{C}$ at a heating rate of $10{ }^{\circ} \mathrm{C} / \mathrm{min}$ under constant purging of nitrogen at $4 \mathrm{~mL} / \mathrm{min}$. An empty aluminium cup was used as a reference.
The morphology of each thoroughly dried membrane surface was studied by SEM using a LEO1430 VP scanning electron microscope (Leo Electron Microscopy Ltd., England). Prior to the microscopy studies, the surface was sputter coated with gold.

Surface topography of non-cross-linked and cross-linked chitosan membranes was examined by an AFM MultiMode Scanning Probe Microscope Nanoscope IIIa (Digital Instruments Veeco Metrology Group, Santa Barbara, CA) operating in the tapping mode in air, at room temperature. The roughness parameters, such as the root mean square $\left(R_{\mathrm{q}}\right)$ and the roughness average $\left(R_{\mathrm{a}}\right)$, were calculated for a scanned area $5 \times$ $5 \mu \mathrm{m}^{2}$ using Nanoscope software.

The elemental content of each membrane was characterized using a CHNS Vario EL Analyzer (Elementar Analysesysteme GmbH, Germany).

\section{Swelling measurements}

All membrane specimens were thoroughly dried before swelling. Dynamic swelling experiments were performed by immersing dry hydrogel membrane samples in buffer solutions at $37.0 \pm 0.1{ }^{\circ} \mathrm{C}$ (in a thermostated bath) and measuring their weight gain as a function of time. At certain intervals the membrane samples were removed, blotted with filter paper to eliminate excess solvent from the surface and weighed. The measurements were continued until a constant weight was reached for each sample.

The swelling ratio $(S)$ at different times was expressed as the grams of solvent sorbed per gram of dry membrane and was calculated using Eq. (1):

$S=\frac{M_{t}-M_{0}}{M_{0}}$

where $M_{0}$ is the mass of the dry sample and $M_{t}$ is the mass of the swollen sample at time $t$. The swelling ratio after the hydrogel membrane had swollen to equilibrium in swelling me$\operatorname{dium}\left(S_{\text {eq }}\right)$ was calculated using Eq. (2):

$S_{e q}=\frac{M_{e q}-M_{0}}{M_{0}}$

where $M_{\mathrm{eq}}$ is the mass of the swollen membrane sample at equilibrium.

To obtain a mean value of $S$ at any time $t$ and a mean value of $S_{\text {eq }}$ all experiments were performed at least three times for each membrane. Standard deviations were less than $5 \%$.

In swelling experiments different buffered solutions of constant ionic strength were used. These were as follows: hydrochloric acid solutions ( $\mathrm{pH} 1.2,1.7,2.2), 10 \mathrm{mM}$ acetic acid/sodium acetate solutions $(\mathrm{pH} \mathrm{3.6,4.4} \mathrm{and} \mathrm{5.6)} \mathrm{and}$ $10 \mathrm{mM}$ Tris buffered solutions ( $\mathrm{pH} \mathrm{6.5,} \mathrm{7.4,} 8.5$ and 9.5). The ionic strength of these buffer solutions was carefully 
adjusted to $0.145 \mathrm{M}$ by adding appropriate amounts of sodium chloride.

\section{Results and discussion}

\section{Structural characterization of hydrogel membranes by FTIR spectroscopy, X-ray spectroscopy and elemental analysis}

FTIR spectra of non-cross-linked and cross-linked chitosan membranes are presented in Fig. 2. Both singly and doubly cross-linked chitosan membranes show spectra that are different from those of non-cross-linked chitosan membrane. The observed changes refer first of all to the 3500-3150 and 1800$1550 \mathrm{~cm}^{-1}$ regions. After adding cross-linking agents (GA or GA and SA) there are changes in the intensity and width of the band at about $3430 \mathrm{~cm}^{-1}(\mathrm{O}-\mathrm{H}$ and $\mathrm{N}-\mathrm{H}$ stretching vibrations of functional groups engaged in hydrogen bonds [7]), which seems to indicate that some hydrogen bonds in the chitosan structure are destroyed and new hydrogen bonds between $\mathrm{Ch}$ and $\mathrm{GA}$ or $\mathrm{Ch}$ and $\mathrm{SA}$ are formed. Moreover, after the addition of $\mathrm{GA}$, absorption bands of chitosan at $1656 \mathrm{~cm}^{-1}(\mathrm{C}=\mathrm{O}$ stretching in amide group, amide I vibration), $1598 \mathrm{~cm}^{-1}$ ($\mathrm{NH}_{2}$ bending in non-acetylated 2-aminoglucose primary amine) and $1560 \mathrm{~cm}^{-1}(\mathrm{~N}-\mathrm{H}$ bending in amide group, amide II vibration [8]) change their positions. The peak at $1656 \mathrm{~cm}^{-1}$ shifts to $1648 \mathrm{~cm}^{-1}$ and in the region of about $1600-1560 \mathrm{~cm}^{-1}$ a broad band with submaxima at about 1595 and $1566 \mathrm{~cm}^{-1}$ is observed. As we have discussed earlier [6], the band at $1648 \mathrm{~cm}^{-1}$ is most probably composed of the amide I band of chitosan and the $\mathrm{C}=\mathrm{N}$ stretching band of a Schiff base. Schiff bases, depending on the compound, absorb in the range $1620-1660 \mathrm{~cm}^{-1}$ [9]. The lack of a band at ca. $1715 \mathrm{~cm}^{-1}$, related to the free aldehyde group [7], indicates that under the experimental conditions GA completely reacted with chitosan and imines (Schiff bases) were formed. The change of the chitosan membrane colour from transparent to yellow also confirms the formation of cross-links between $\mathrm{Ch}$ and GA. Two main bands that can be seen in the FTIR spectrum of $\mathrm{Ch} / \mathrm{GA} / \mathrm{SA}$ (Fig. 2) in the frequency range of 1650 $1500 \mathrm{~cm}^{-1}$ (i.e. at 1641 and $1538 \mathrm{~cm}^{-1}$ ) derive mainly from the asymmetric and symmetric $\mathrm{N}-\mathrm{H}$ deformation vibrations in protonated amines, but the initial amide I, amide II and imine bands are possibly overlapped by these vibrations [7]. The new band observed at $617 \mathrm{~cm}^{-1}$ in the FTIR spectrum of $\mathrm{Ch} / \mathrm{GA} / \mathrm{SA}$ can be attributed to the $\mathrm{S}-\mathrm{O}$ bending vibration in $\mathrm{SO}_{4}{ }^{2-}$ ions [7]. The FTIR analysis of $\mathrm{Ch} / \mathrm{GA}$ and $\mathrm{Ch} / \mathrm{GA} / \mathrm{SA}$ specimens confirms that cross-linking takes place by the reaction of amine groups of chitosan with aldehyde groups of glutaraldehyde and/or amine groups of chitosan and sulfate groups of sulfuric acid, as presented in Fig. 1.

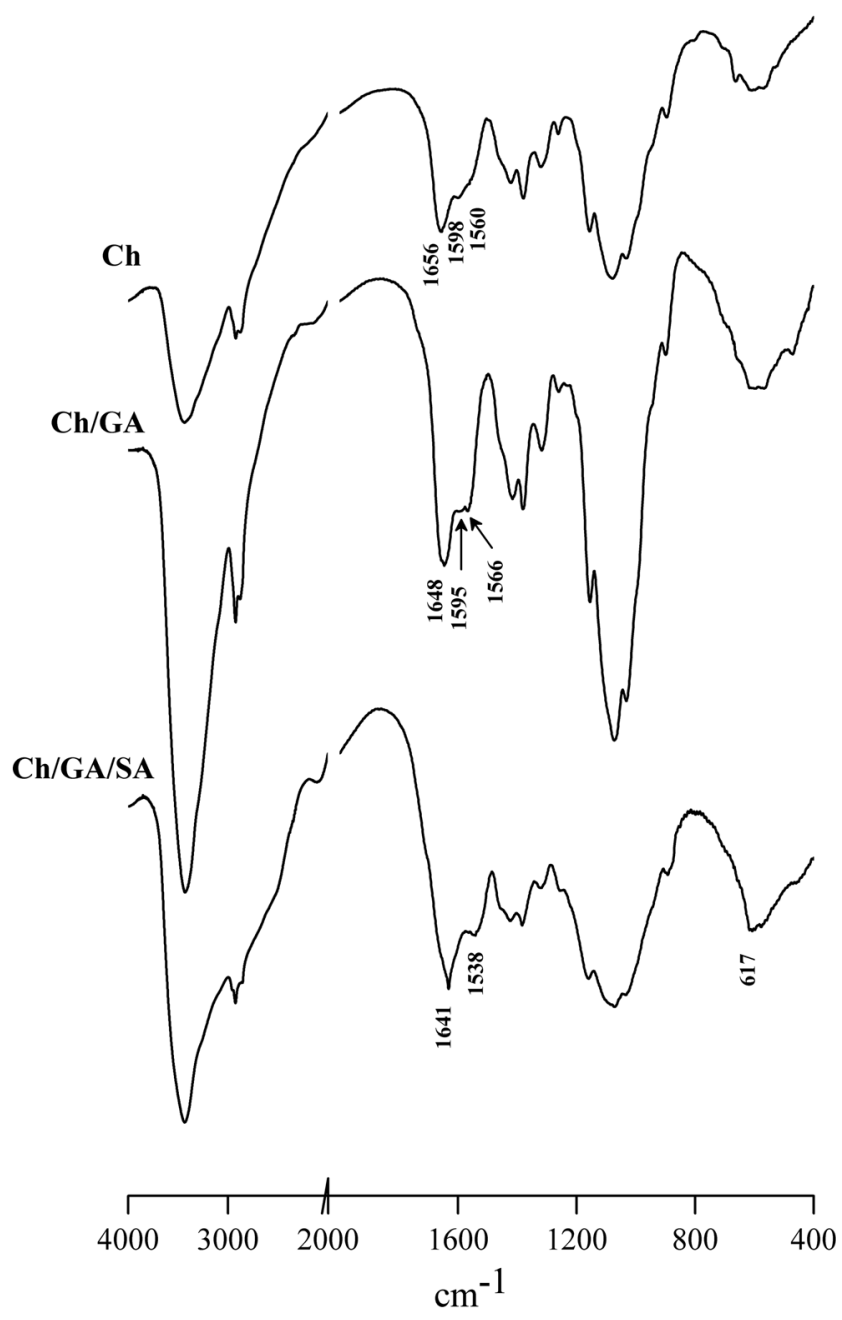

Fig. 2 FTIR spectra of $\mathrm{Ch}, \mathrm{Ch} / \mathrm{GA}$ and $\mathrm{Ch} / \mathrm{GA} / \mathrm{SA}$ membranes

We have drawn conclusions on the degree of ionic crosslinking and the content of ionisable groups in $\mathrm{Ch} / \mathrm{GA} / \mathrm{SA}$ membranes from elemental analysis. The results of elemental analysis of $\mathrm{Ch}, \mathrm{Ch} / \mathrm{GA}$ and $\mathrm{Ch} / \mathrm{GA} / \mathrm{SA}$ membranes are listed in Table 1. The table presents data for $\mathrm{Ch} / \mathrm{GA}$ membrane (of average thickness $50 \pm 3 \mu \mathrm{m}$ ) immersed in sulfuric acid solution for different times. It can be observed that both the sulfur content (and thus sulfate group content), as well as the molar ratio of sulfur to nitrogen, increased very quickly during the first $10 \mathrm{~min}$ of acid treatment. For longer periods of time these values increased with time very slowly. The molar ratio of sulfur to nitrogen in $\mathrm{Ch} / \mathrm{GA} / \mathrm{SA}(60 \mathrm{~min}), \mathrm{Ch} / \mathrm{GA} / \mathrm{SA}$ (120 $\mathrm{min})$ and $\mathrm{Ch} / \mathrm{GA} / \mathrm{SA}(24 \mathrm{~h})$ was practically the same. Thus, the degree of ionic cross-linking of those membranes was also very similar. In further experiments only the $\mathrm{Ch} / \mathrm{GA} /$ SA (24 h) membrane was used.

$\mathrm{X}$-ray spectra of non-cross-linked and cross-linked membranes (Fig. 3) indicate that the crystallinity of the chitosan decreased after its cross-linking with glutaraldehyde or glutaraldehyde and sulfuric acid, but cross-linked membranes retained their semicrystalline morphology. The X-ray pattern 
Table 1 Results of elemental analysis of $\mathrm{Ch}, \mathrm{Ch} / \mathrm{GA}$ and $\mathrm{Ch} / \mathrm{GA} / \mathrm{SA}$ membranes

\begin{tabular}{llll}
\hline Membrane & \multicolumn{2}{l}{ Content of elements $(w t \%)$} & $n_{\mathrm{S}} / n_{\mathrm{N}}{ }^{\mathrm{a}}$ \\
\cline { 2 - 3 } & $\mathrm{N}$ & $\mathrm{S}$ \\
\hline $\mathrm{Ch}$ & 6.76 & & \\
$\mathrm{Ch} / \mathrm{GA}$ & 6.93 & & \\
$\mathrm{Ch} / \mathrm{GA} / \mathrm{SA}(10 \mathrm{~min})$ & 6.05 & 5.90 & 0.43 \\
$\mathrm{Ch} / \mathrm{GA} / \mathrm{SA}(60 \mathrm{~min})$ & 5.39 & 7.49 & 0.61 \\
$\mathrm{Ch} / \mathrm{GA} / \mathrm{SA}(120 \mathrm{~min})$ & 5.40 & 7.55 & 0.61 \\
$\mathrm{Ch} / \mathrm{GA} / \mathrm{SA}(24 \mathrm{~h})$ & 5.45 & 7.59 & 0.61 \\
\hline
\end{tabular}

${ }^{\mathrm{a}}$ Molar ratio of sulfur to nitrogen

of Ch shows three major crystalline peaks: the two weaker peaks at $2 \theta \approx 10^{\circ}$ and $2 \theta \approx 15^{\circ}$ and the strongest one at $2 \theta \approx$ $20^{\circ}$, characteristic for the crystalline forms I, II and anhydrous form [10]. In the case of cross-linked membranes these crystalline peaks, mainly the peak at $2 \theta \approx 20^{\circ}$, became wider and weaker.

\section{Surface morphology of hydrogel membranes}

SEM images of $\mathrm{Ch}, \mathrm{Ch} / \mathrm{GA}$ and $\mathrm{Ch} / \mathrm{GA} / \mathrm{SA}$ membranes showed that their surface morphology before and after crosslinking was similar (Fig. 4a). The polymer top layer had a smooth, homogeneous and flat surface without any visible pores. Thus, all studied membranes can be characterized as dense ones.

Three-dimensional AFM images of non-cross-linked and cross-linked chitosan membranes taken in a scan area of $5 \times$ $5 \mu^{2}$, are shown in Fig. $4 \mathrm{~b}$. The results relating to the roughness analysis are also presented. Non-cross-linked chitosan

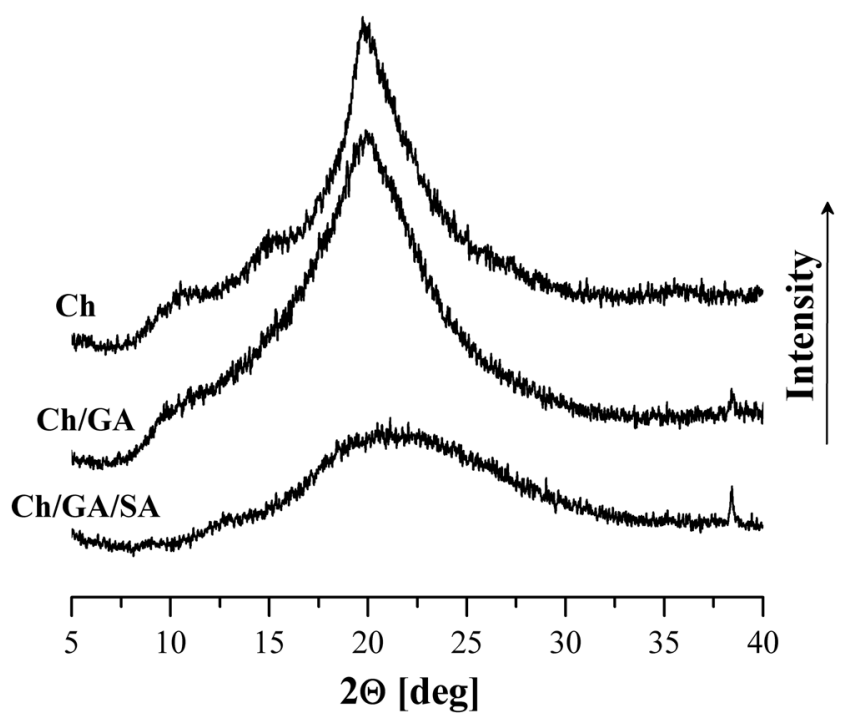

Fig. 3 Wide-angle X-ray diffraction spectra of $\mathrm{Ch}, \mathrm{Ch} / \mathrm{GA}$ and $\mathrm{Ch} / \mathrm{GA}$ / SA membranes membrane has an $R_{\mathrm{q}}$ value of $2.08 \pm 0.63 \mathrm{~nm}$ and $R_{\mathrm{a}}$ value of $1.65 \pm 0.61 \mathrm{~nm}$, indicating roughness at the nanometer scale. The cross-linked chitosan membranes presented higher roughness values as compared to non-cross-linked ones.

\section{Thermal properties of hydrogel membranes}

Figure 5a shows DTG curves for non-cross-linked and crosslinked chitosan membranes. The non-cross-linked chitosan and GA-cross-linked chitosan membranes show a two-stage decomposition process, but the doubly cross-linked chitosan membrane shows a three-stage thermal degradation. Similar results were obtained earlier for chitosan and cross-linked chitosan [11-13]. For all polymer membranes the first stage starts at about $50^{\circ} \mathrm{C}$ and continues up to $180^{\circ} \mathrm{C}$ and is accompanied by a weight loss ranging from 1 to $4 \%$. This stage can be assigned to the evaporation of the residual, physically adsorbed water present in the polymer samples, which could not be removed completely by drying [11, 12], The content of this water is a function of the morphology, crystallinity and hydrophilicity of the polymers.

The second and third stages of polymer degradation correspond to the thermal decomposition of chitosan or singly and doubly cross-linked chitosan, vaporization and elimination of volatile products. For pure chitosan the second stage starts at $240{ }^{\circ} \mathrm{C}$, reaches a maximum at $301{ }^{\circ} \mathrm{C}$ and ends at $400{ }^{\circ} \mathrm{C}$. In this decomposition stage the weight loss of chitosan reaches $49 \%$. The predominant stage of thermal degradation of $\mathrm{Ch} /$ GA membrane appears at $197-400{ }^{\circ} \mathrm{C}$ range (with $T_{\max }=$ $279{ }^{\circ} \mathrm{C}$ ), during which $43 \%$ weight loss is observed. The thermal degradation process of $\mathrm{Ch} / \mathrm{GA} / \mathrm{SA}$ membrane seems to be more complex. In the DTG curve in the temperature range $180-400{ }^{\circ} \mathrm{C}$, two peaks (with $T_{\max }=206$ and $263{ }^{\circ} \mathrm{C}$ ) are observed, which can be related to the second and third stage of thermal degradation, respectively. In the range of $180-238{ }^{\circ} \mathrm{C}$ the mass loss of chitosan reaches $24 \%$, whereas in the range of $238-400{ }^{\circ} \mathrm{C}$ a $28 \%$ drop of membrane mass is observed. Three thermal decomposition steps were observed earlier by Osifo and Masala for chitosan membranes modified by cross-linking with sulfuric acid [13].

Thermal degradation of chitosan is a complex reaction. Different decomposition products were observed by TGA coupled with FTIR spectroscopy, mass spectrometry and chromatography $[12,14]$. According to literature data pyrolysis of chitosan starts by a random splitting of the glycosidic bonds, followed by a further decomposition to acetic, butyric and lower fatty acids $[11,12]$. It can be supposed that in the observed steps of thermal degradation of cross-linked membranes there are liberated molecular degradation products both of chitosan and cross-linking agents.

DTG results show that the cross-linked samples start to decompose at lower temperature. Similar results were reported earlier by Neto et al. [11] and Yang and Su [15] for chitosan 


\section{Ch}

(A)

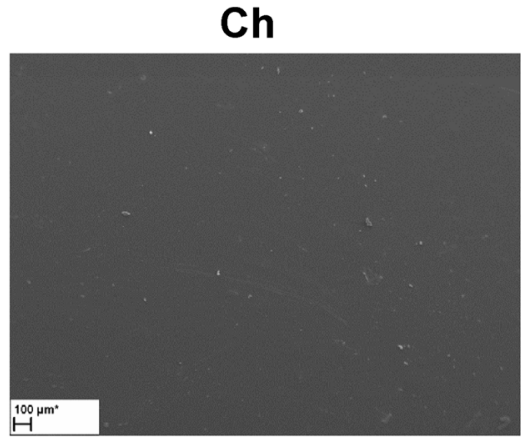

(B)

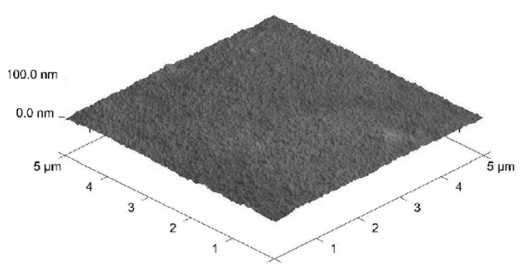

$$
\begin{aligned}
& R_{q}=(2.08 \pm 0.63) \mathrm{nm} \\
& R_{a}=(1.65 \pm 0.61) \mathrm{nm}
\end{aligned}
$$

Ch/GA
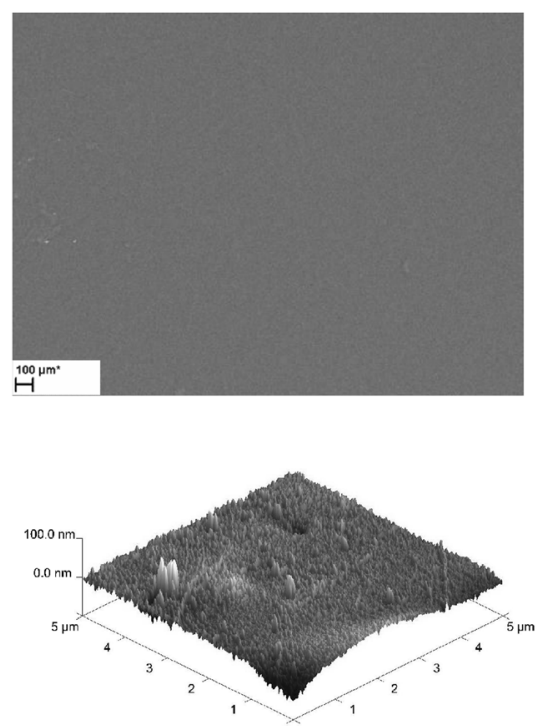

$R_{q}=(9.18 \pm 2.15) \mathrm{nm}$ $R_{\mathrm{a}}=(5.67 \pm 1.98) \mathrm{nm}$

\section{Ch/GA/SA}
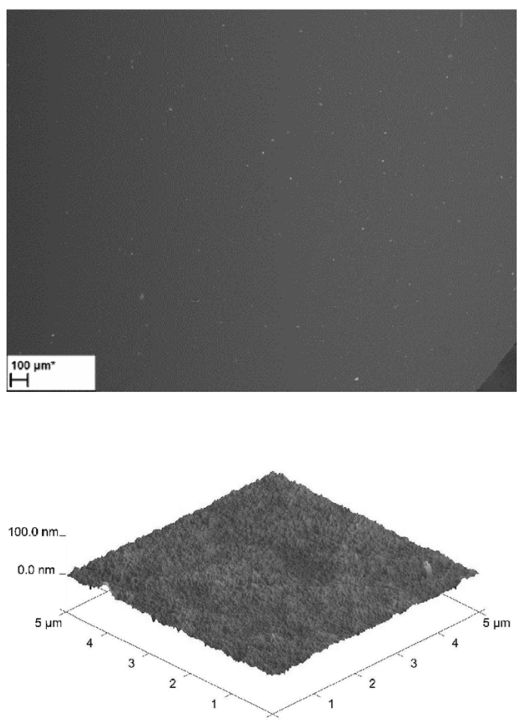

$R_{q}=(3.16 \pm 2.65) \mathrm{nm}$ $R_{a}=(1.92 \pm 1.47) \mathrm{nm}$

Fig. 4 SEM (a) and AFM (b) images of $\mathrm{Ch}, \mathrm{Ch} / \mathrm{GA}$ and $\mathrm{Ch} / \mathrm{GA} / \mathrm{SA}$ membranes
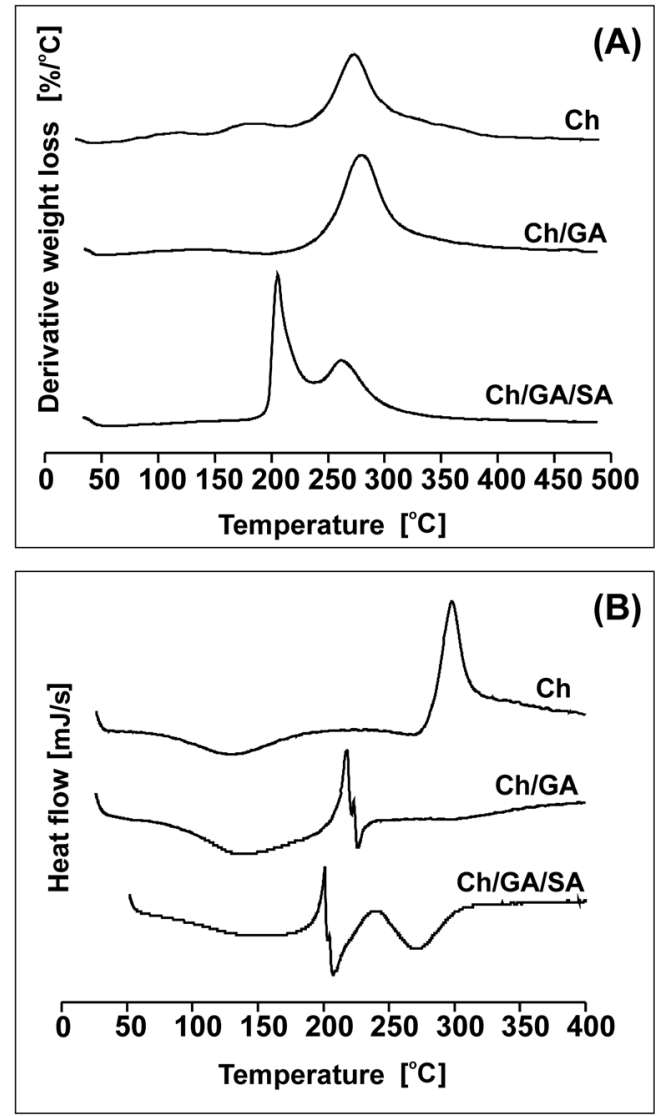

Fig. 5 DTG (a) and DSC (b) curves for $\mathrm{Ch}, \mathrm{Ch} / \mathrm{GA}$ and $\mathrm{Ch} / \mathrm{GA} / \mathrm{SA}$ membranes cross-linked by GA and by Mukoma et al. [16] for chitosan cross-linked by sulfuric acid. Considering the temperature at which thermal degradation starts as a criterion of the thermal stability of the membrane, the thermal stability decreases according to the order $\mathrm{Ch}>\mathrm{Ch} / \mathrm{GA}>\mathrm{Ch} / \mathrm{GA} / \mathrm{SA}$. According to Trimukhe and Varma [17] both chemical modification and metal complexation lead to a decrease of thermal stability of chitosan.

DSC thermograms of $\mathrm{Ch}, \mathrm{Ch} / \mathrm{GA}$ and $\mathrm{Ch} / \mathrm{GA} / \mathrm{SA}$ membranes are shown in Fig. 5b. The major thermal processes occurred between 50 and $350^{\circ} \mathrm{C}$. The broad endothermic peak between 50 and $200{ }^{\circ} \mathrm{C}$ can be attributed to the evaporation of water bonded to the chitosan chains and functional groups of cross-linking agents by different kinds of physical bonds (hydrogen bonds, electrostatic interactions) [18, 19]. Chitosan membrane underwent exothermic decomposition at higher temperatures. The exothermic peak appeared at 301, 218 and $201{ }^{\circ} \mathrm{C}$ for $\mathrm{Ch}, \mathrm{Ch} / \mathrm{GA}$ and $\mathrm{Ch} / \mathrm{GA} / \mathrm{SA}$ membrane, respectively. This peak corresponds to degradation of chitosan $[18,19]$. In the case of cross-linked membranes DSC thermograms are more complex, because additional exothermic and endothermic peaks are observed at temperatures above $200{ }^{\circ} \mathrm{C}$. A similar phenomenon was observed earlier by others [14, 19, 20].

DSC results indicate that the thermal stability of crosslinked membranes is lower than that of non-cross-linked ones and thus confirm the TGA results presented above. Our DSC results correspond with literature data for chitosan crosslinked by glutaraldehyde or chitosan cross-linked by sulfuric 
acid $[15,20]$. For cross-linked membranes DSC thermograms are more complex. Additional exotherms appeared at higher temperatures.

\section{Swelling kinetics of hydrogel membranes}

Chitosan membrane swells when it is brought into contact with a buffered aqueous solution. Swelling of the polymer membrane continues until the forces due to swelling of the polymer balance the osmotic pressure, driving the solvent into the swollen polymer. The swelling process of hydrogels is a complicated phenomenon and involves three successive steps: (i) the diffusion of water molecules into the polymer network, (ii) the relaxation of hydrated polymer chains and (iii) the expansion of the polymer network into the surrounding aqueous solution [21]. Figures 6 and 7 present the dynamic swelling data for non-cross-linked chitosan membrane and crosslinked chitosan membranes in buffered aqueous solutions of constant ionic strength $\left(0.145 \mathrm{M}\right.$ at $\left.37^{\circ} \mathrm{C}\right)$. Because the noncross-linked chitosan membrane swelled and disintegrated quickly in acidic solutions, it was not possible to study the kinetics of water uptake and the mechanism of water transport into this membrane at $\mathrm{pH}<6.5$. Each point in Figs. 6 and 7 is an average of three separate experiments.

The swelling isotherms for $\mathrm{Ch}$ (in neutral and basic media), $\mathrm{Ch} / \mathrm{GA}$ and $\mathrm{Ch} / \mathrm{GA} / \mathrm{SA}$ membranes are similar. For each buffer solution the swelling ratio increases with time until a certain point, when it becomes constant, i.e. the equilibrium state is reached. At the beginning the swelling is very fast. Figure 8 shows the equilibrium swelling ratio $S_{\text {eq }}$ as a function of $\mathrm{pH}$ for $\mathrm{Ch}, \mathrm{Ch} / \mathrm{GA}$ and $\mathrm{Ch} / \mathrm{GA} / \mathrm{SA}$. All chitosan membranes exhibite a pH-responsive swelling. Values of $S_{\text {eq }}$ decrease with increasing $\mathrm{pH}$. Moreover, the results clearly reveal that all membranes undergo drastic mass and/or volume change in the definite $\mathrm{pH}$ range.

Non-cross-linked and cross-linked chitosan membranes belong to the class of ionic hydrogel membranes. As discussed earlier by Peppas et al. [22, 23], Berger et al. [24] and Baipai and Singh [25], the equilibrium swelling of ionic hydrogels depends on the network structure, degree of cross-linking, hydrophilicity and ionisation of the functional groups. The swelling behaviour of cross-linked hydrogels also depends on the degree of cross-linking and nature of the cross-linking agent $[23,26]$. Swelling of the environmental-sensitive hydrogels can be affected by specific stimuli. Ionic strength and $\mathrm{pH}$ affect the swelling of ionic strength- and $\mathrm{pH}$-sensitive hydrogels, respectively [22]. $\mathrm{Ch}, \mathrm{Ch} / \mathrm{GA}$ and $\mathrm{Ch} / \mathrm{GA} / \mathrm{SA}$ hydrogel membranes differ both in their molecular structure (hydrophilic/hydrophobic properties), degree of cross-linking and content of ionisable groups, as well as in supermolecular structure (degree of crystallinity). All membranes were semicrystalline polymers (Fig. 3), but crystallinity of the Ch membrane decreased after cross-linking with glutaraldehyde and

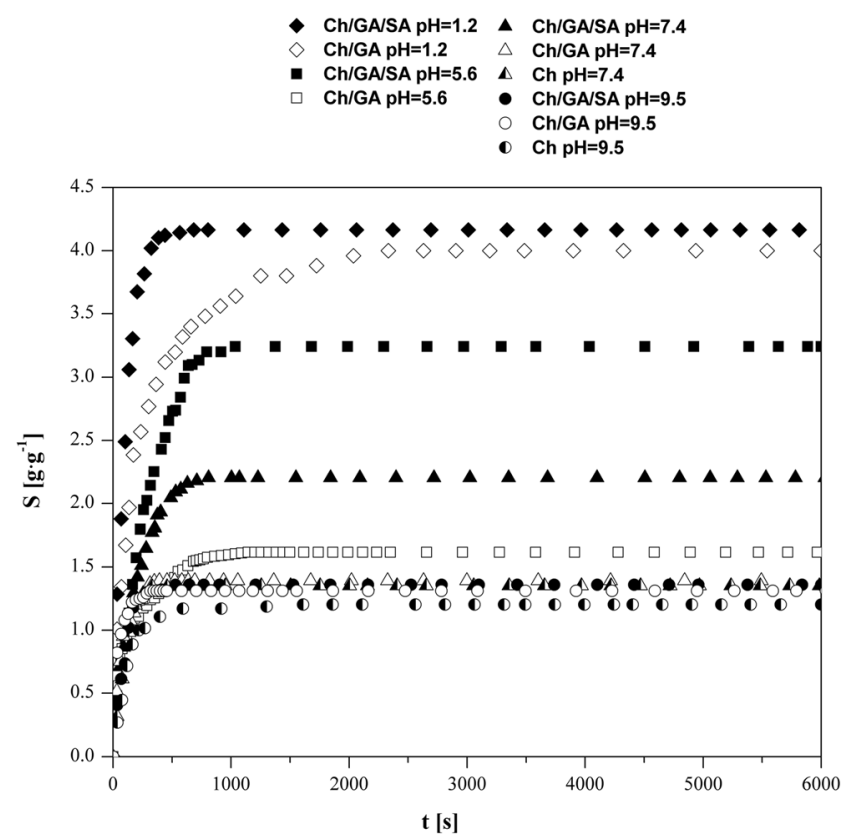

Fig. 6 Swelling curves of $\mathrm{Ch}, \mathrm{Ch} / \mathrm{GA}$ and $\mathrm{Ch} / \mathrm{GA} / \mathrm{SA}$ membranes in selected buffer solutions $\left(T=37^{\circ} \mathrm{C}, I=0.145 \mathrm{M}\right)$

sulfuric acid. The lower crystallinity enhances the water molecules' accessibility. Bearing in mind some differences in molecular and supermolecular structure of non-cross-linked and cross-linked chitosan membranes and all factors affecting the swelling of ionic hydrogels, we could look for some differences in $\mathrm{Ch}, \mathrm{Ch} / \mathrm{GA}, \mathrm{Ch} / \mathrm{GA} / \mathrm{SA}$ swelling behaviour. Degree of ionisation of chitosan strongly depends on the $\mathrm{pH}$ of the swelling solutions [4] and the observed drastic mass/volume changes in the definite $\mathrm{pH}$ range result from the protonation or deprotonation of amine groups of chitosan units within the definite $\mathrm{pH}$ range.

The high degree of swelling in acidic solutions observed for all studied hydrogel membranes (Figs. 6 and 7) can be

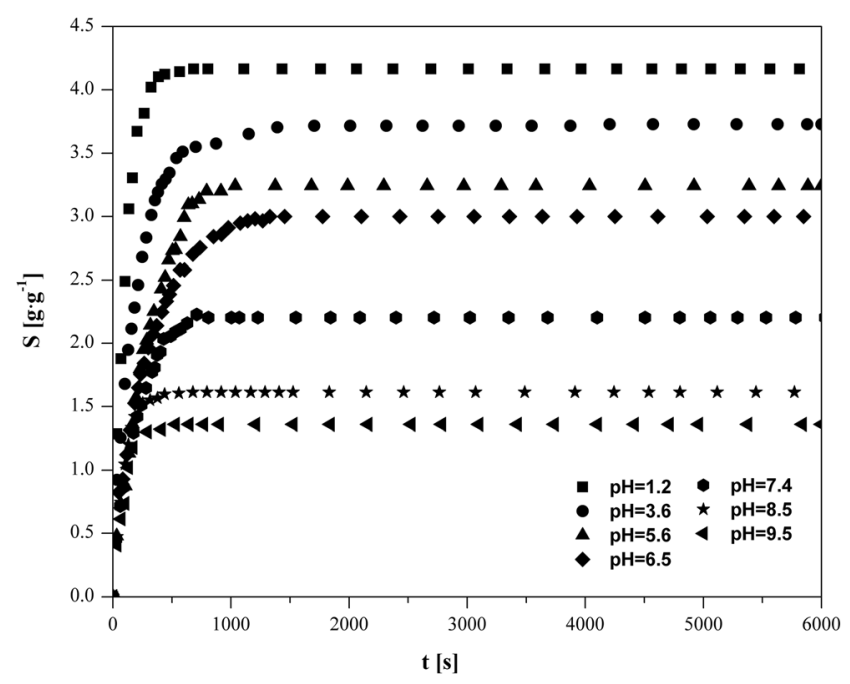

Fig. 7 Swelling curves of $\mathrm{Ch} / \mathrm{GA} / \mathrm{SA}$ membrane in all studied buffer solutions $\left(T=37^{\circ} \mathrm{C}, I=0.145 \mathrm{M}\right)$ 


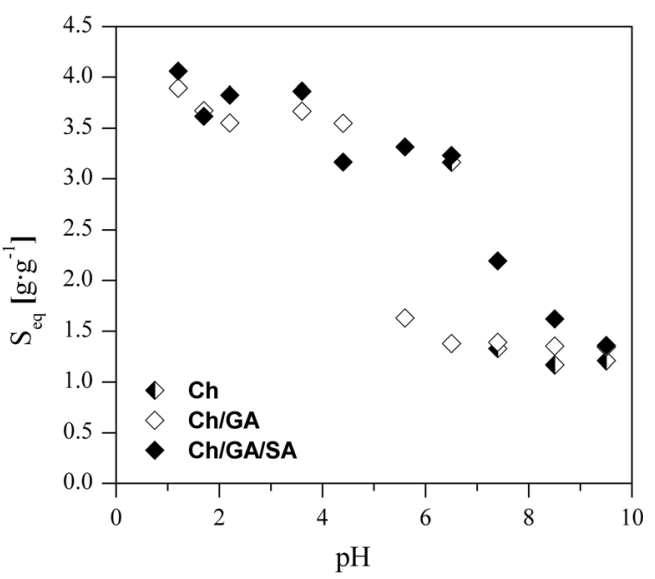

Fig. 8 Equilibrium swelling ratio of $\mathrm{Ch}, \mathrm{Ch} / \mathrm{GA}$ and $\mathrm{Ch} / \mathrm{GA} / \mathrm{SA}$ membranes in buffer solutions of various $\mathrm{pH}$

attributed to the high degree of protonation of amine groups of Ch. Chitosan is a weak polybase with an intrinsic $\mathrm{p} K_{\mathrm{a}}$ of about 6.5 [27]. Thus, in buffer solution of low $\mathrm{pH}$ the most functional amine groups of chitosan are protonated. The electrostatic repulsion between charged chitosan chains leads to expansion of the polymer network, diffusion of buffer inside the gel and swelling. When $\mathrm{pH}$ of the solution increases then the degree of ionisation of chitosan decreases and a gel with a more compact structure and low $S_{\mathrm{eq}}$ is formed. Thus, the mechanism of $\mathrm{pH}$-sensitive swelling of non-cross-linked and cross-linked chitosan membranes is determined mainly by ionic interactions (electrostatic repulsion) between ionised chitosan chains.

The inflection point of the S-shaped curves of equilibrium water uptake against $\mathrm{pH}$, presented in Fig. 8, can be used to estimate an approximate $\mathrm{p} K_{\mathrm{a}}$ of the gel. This point lies between $\mathrm{pH} 5$ and 6 for $\mathrm{Ch} / \mathrm{GA}$ membrane and between $\mathrm{pH} 6$ and 7 for $\mathrm{Ch} / \mathrm{GA} / \mathrm{SA}$. Values of $\mathrm{p} K_{\mathrm{a}}$ reported for chitosan range between 6.1 and 7 , depending on their degree of deacetylation and molecular weight [28 and literature cited therein], but very often an intrinsic dissociation constant given by Domard and equal to 6.5 is cited [27]. It can be concluded that the incorporation of GA and SA and the formation of a network structure contribute to the observed $\mathrm{p} K_{\mathrm{a}}$ of the gels. Some differences between $\mathrm{p} K_{\mathrm{a}}$ of the crosslinked and non-cross-linked anionic gels were observed earlier by Khare and Peppas [29] and Bajpai and Singh [25] and were attributed to the cross-linked structure of the gels.

To characterize the effect of the $\mathrm{pH}$ of swelling medium on the kinetics of water uptake of $\mathrm{Ch}, \mathrm{Ch} / \mathrm{GA}$ and $\mathrm{Ch} / \mathrm{GA} / \mathrm{SA}$ membranes, kinetic modelling was conducted on the basis of the Fickian diffusion law and Schott's second-order kinetic equation.

To determine the type of diffusion of water into the hydrogels (water transport mechanism) we applied the simple and commonly used method, based on the power-law expression [Eq. (3)] given by Peppas et al. [30, 31]:

$\frac{M_{t}}{M_{e q}}=k t^{n}$

where $M_{t}$ is the amount of water absorbed at time $t, M_{\mathrm{eq}}$ is the amount of water absorbed at equilibrium, $k$ is a characteristic constant dependent on the structure of the polymer network, and $n$ is the exponent that describes the type of diffusion (mode of transport) of the penetrant into the hydrogel. This expression describing both Fickian and non-Fickian transport behaviour of penetrant into polymer can be applied only to the initial stages of swelling, i.e. up to a $60 \%$ increase in the mass of hydrogel $\left(M_{t} / M_{\mathrm{eq}} \leq 0.6\right)[31]$.

The phenomenon of water sorption by hydrogels depends on the diffusion of water molecules into the gel matrix and subsequent relaxation of macromolecular chains of the hydrogel $[30,31]$. The mechanism of water transport in a swelling hydrogel is greatly affected by many factors, such as equilibrium water content, chemical composition of the hydrogel, swelling rate, etc. [30, 32]. In general, three models are used to describe transport phenomena into polymer networks [33-37]. These models, proposed by Alfrey et al. [38], are based on relative rates of penetrant diffusion and polymer chain relaxation:

1. Case I (or Fickian diffusion) in which solvent diffusion rate $R_{\text {diff }}$ is slower than the polymer relaxation rate $R_{\text {relax }}$ $\left(R_{\text {diff }} \ll R_{\text {relax }}\right)$.

2. Case II diffusion (or non-Fickian diffusion) in which the solvent diffusion rate is faster than the polymer relaxation rate $\left(R_{\text {diff }} \gg R_{\text {relax }}\right)$.

3. Case III (or anomalous diffusion, non-Fickian diffusion) which occurs when the solvent diffusion and the polymer relaxation rate are about the same order of magnitude $(R$ diff $\approx R_{\text {relax }}$.

Fickian diffusion is often observed in polymer networks when the temperature is much above the glass transition temperature of the polymer, $T_{\mathrm{g}}$. When the polymer is in a rubbery state, the polymer chains have a higher mobility that allows easier penetration of the solvent. Therefore, Fickian diffusion is characterized by $R_{\text {diff }}$ being much lower than $R_{\text {relax }}$. NonFickian diffusion processes are mainly observed in polymer networks when the temperature is below the glass transition temperature of the polymer. At $T<T_{\mathrm{g}}$ polymer chains are not sufficiently mobile to permit immediate penetration of the solvent into the polymer core. As presented above, the main difference between cases II and III concerns the solvent diffusion rate.

Equation (3) describes both Fickian and non-Fickian transport behaviour in thin polymer slabs or discs. Parameter $n$ depends on the geometrical shape of the hydrogel matrix: 
for a planar geometry, the value of $n=0.5$ indicates a Fickian diffusion mechanism (case I); $n=1.0$, case II transport; and 0.5 $<n<1.0$, case III (anomalous or non-Fickian) diffusion mechanism, where both diffusion and polymer relaxation control the overall rate of water uptake [22, 33-37]. Occasionally, values of $n>1$ and $n<0.5$ have been observed, which are regarded as super case II diffusion [22, 35-37] and pseudoFickian (or less-Fickian) diffusion $[35,36]$.

To characterize the water transport mechanism the swelling curves were fitted to the following equation:

$\log \frac{M_{t}}{M_{e q}}=\log k+n \log t$

Figure 9 shows the typical plots of $\log \left(M_{t} / M_{\mathrm{eq}}\right)$ versus $\log t$ for $\mathrm{Ch} / \mathrm{GA} / \mathrm{SA}$ hydrogels in three different buffer solutions. The obtained results exhibit good linear correlations. As presented in Table 2, determination coefficients $R^{2}$ are greater than 0.99 . Values of the exponent $n$, which were calculated from the slope of the plots of $\log \left(M_{t} / M_{\mathrm{eq}}\right)$ versus $\log t$, range between 0.81 and 0.99 for $\mathrm{Ch}$ membrane, between 0.33 and 0.55 for $\mathrm{Ch} / \mathrm{GA}$ membrane and between 0.57 and $0.75 \mathrm{for} \mathrm{Ch} /$ GA/SA. For all membranes, coefficient $n$ depends on the $\mathrm{pH}$ of the buffer solution. The dependence of $n$ on $\mathrm{pH}$ is shown in Fig. 10.

The obtained results indicate that $\mathrm{Ch}$ membrane shows a non-Fickian swelling behaviour in all buffer solutions. Thus, both diffusion and polymer relaxation control the overall rate of water uptake. For $\mathrm{Ch} / \mathrm{GA}$ membrane, parameter $n$ is less than 0.5 in acidic solutions and is close to 0.5 for $\mathrm{pH} \geq 6.5$, so the diffusion can be considered as less-Fickian or Fickian, respectively. In the case of $\mathrm{Ch} / \mathrm{GA} / \mathrm{SA}$ membrane, values of $n$ are higher than 0.5 in buffer solutions of $\mathrm{pH}<6.5$, but they are close to 0.5 in solutions of $\mathrm{pH} \geq 6.5$. This indicates a shift of the water transport mechanism from anomalous to Fickian type, i.e. from relaxation-controlled to diffusion-controlled. The effect of $\mathrm{pH}$ on the mechanism of water transport into ionic hydrogels was studied earlier by several researchers [32, 39-41]. It was found that the solvent transport mechanism became non-Fickian (more relaxation-controlled) as gel ionisation became prominent. As discussed earlier by Peppas et al. [29, 31, 32], the dynamic swelling behaviour of hydrogels is dependent on the relative contribution of penetrant diffusion and polymer relaxation. In the ionic hydrogels the ionisation of functional groups may control the water diffusion process, thus affecting the relative magnitude of diffusion and relaxation times [29,42]. An increase in the degree of ionisation results in the electrostatic repulsion between ionised functional groups, leading to chain expansion, which in turn affects macromolecular chain relaxation. Thus, the swelling mechanism becomes non-Fickian (more relaxationcontrolled) when the ionisation of hydrogel increases. For anionic hydrogels non-Fickian (anomalous) transport was

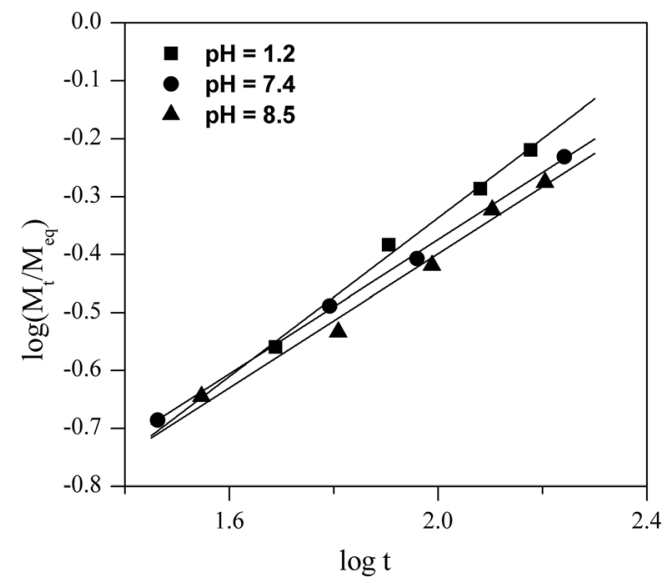

Fig. 9 Plots of $\log \left(M_{t} / M_{\text {eq }}\right)$ versus $\log (t)$ for $\mathrm{Ch} / \mathrm{GA} / \mathrm{SA}$ membrane in buffer solutions of $\mathrm{pH} 1.2,7.4$ and 8.5

Table 2 Swelling kinetic parameters for $\mathrm{Ch}, \mathrm{Ch} / \mathrm{GA}$ and $\mathrm{Ch} / \mathrm{GA} / \mathrm{SA}$ membranes in buffer solutions of various $\mathrm{pH}\left(T=37^{\circ} \mathrm{C}, I=0.145 \mathrm{M}\right)$

\begin{tabular}{|c|c|c|c|c|c|c|}
\hline Sample & $\mathrm{pH}$ & $n$ & $S_{\text {eq }}^{\exp }\left(\mathrm{g} \mathrm{g}^{-1}\right)$ & $\begin{array}{l}S_{\mathrm{eq}}^{\text {calc }} \\
\left(\mathrm{g} \mathrm{g}^{-1}\right)\end{array}$ & $\begin{array}{l}k_{\mathrm{S}} \times 10^{3} \\
\left(\mathrm{~s}^{-1}\right)\end{array}$ & $R^{2}$ \\
\hline \multirow[t]{10}{*}{$\mathrm{Ch}$} & 1.2 & & & & & \\
\hline & 1.7 & & & & & \\
\hline & 2.2 & & & & & \\
\hline & 3.6 & & & & & \\
\hline & 4.4 & & & & & \\
\hline & 5.6 & & & & & \\
\hline & 6.5 & 0.99 & 3.16 & 3.24 & 1.4 & 0.9994 \\
\hline & 7.4 & 0.85 & 1.33 & 1.35 & 4.7 & 0.9992 \\
\hline & 8.5 & 0.81 & 1.17 & 1.20 & 2.8 & 0.9985 \\
\hline & 9.5 & 0.85 & 1.21 & 1.23 & 3.7 & 0.9996 \\
\hline \multirow[t]{10}{*}{$\mathrm{Ch} / \mathrm{GA}$} & 1.2 & 0.48 & 3.89 & 3.93 & 3.4 & 0.9999 \\
\hline & 1.7 & 0.40 & 3.67 & 3.77 & 3.4 & 0.9996 \\
\hline & 2.2 & 0.33 & 3.55 & 3.73 & 1.5 & 0.9993 \\
\hline & 3.6 & 0.33 & 3.67 & 3.78 & 1.6 & 0.9994 \\
\hline & 4.4 & 0.37 & 3.55 & 3.57 & 0.5 & 0.9984 \\
\hline & 5.6 & 0.37 & 1.63 & 1.66 & 10.0 & 0.9998 \\
\hline & 6.5 & 0.45 & 1.38 & 1.38 & 8.7 & 0.9999 \\
\hline & 7.4 & 0.54 & 1.39 & 1.40 & 43.0 & 1.0000 \\
\hline & 8.5 & 0.55 & 1.35 & 1.36 & 51.0 & 1.0000 \\
\hline & 9.5 & 0.54 & 1.34 & 1.35 & 60.0 & 0.9999 \\
\hline \multirow{10}{*}{$\begin{array}{c}\mathrm{Ch} / \mathrm{GA} / \\
\mathrm{SA}\end{array}$} & 1.2 & 0.63 & 4.06 & 4.11 & 6.2 & 0.9998 \\
\hline & 1.7 & 0.75 & 3.62 & 3.76 & 3.8 & 0.9989 \\
\hline & 2.2 & 0.65 & 3.83 & 4.12 & 1.0 & 0.9983 \\
\hline & 3.6 & 0.64 & 3.87 & 3.98 & 3.1 & 0.9981 \\
\hline & 4.4 & 0.66 & 3.23 & 3.30 & 3.1 & 0.9998 \\
\hline & 5.6 & 0.68 & 3.31 & 3.41 & 6.8 & 0.9988 \\
\hline & 6.5 & 0.54 & 3.05 & 3.13 & 4.0 & 0.9993 \\
\hline & 7.4 & 0.59 & 2.19 & 2.23 & 8.0 & 0.9996 \\
\hline & 8.5 & 0.59 & 1.62 & 1.64 & 16.0 & 0.9997 \\
\hline & 9.5 & 0.57 & 1.36 & 1.37 & 26.0 & 0.9999 \\
\hline
\end{tabular}




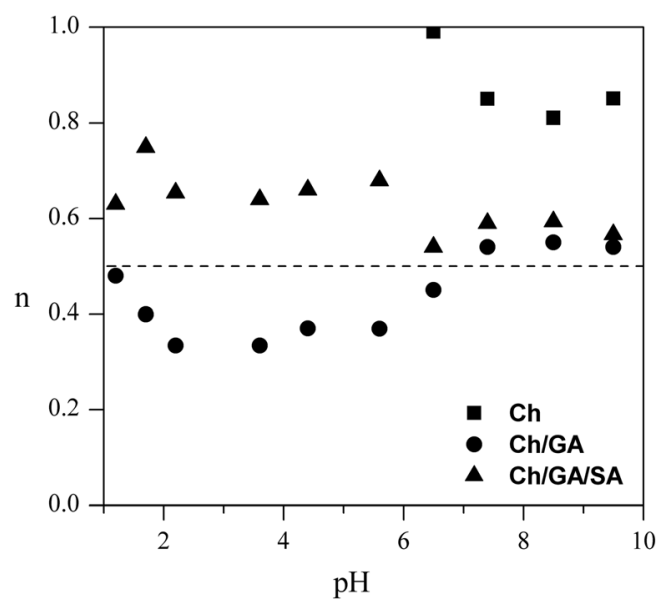

Fig. 10 Effect of $\mathrm{pH}$ on the diffusion exponent $n$ for $\mathrm{Ch}, \mathrm{Ch} / \mathrm{GA}$ and $\mathrm{Ch} /$ GA/SA membranes

observed as the $\mathrm{pH}$ of the surrounding fluid increased above the $\mathrm{p} K_{\mathrm{a}}[32,39-41]$.

In the case of chitosan membranes, with decreasing $\mathrm{pH}$ of buffer solution the protonation of functional amine groups increases. An increase in the degree of ionisation contributes to the electrostatic repulsion between adjacent $\mathrm{NH}_{3}{ }^{+}$groups, leading to chain expansion, which in turn affects macromolecular chain relaxation. Therefore the mechanism of swelling of water into cationic hydrogel (chitosan membrane) becomes more relaxation-controlled as $\mathrm{pH}$ decreases and/or degree of ionisation increases.

For $\mathrm{Ch} / \mathrm{GA}$ membrane values of $n$ are less than 0.5 in acidic solutions $(\mathrm{pH} \leq 6.5)$ and are close to 0.5 at $\mathrm{pH}>6.5$ (Fig. 10). Hence, the overall process can be regarded as less-Fickian or Fickian, respectively. A value of $n=0.5$ is characteristic for a perfectly Fickian process where the rate of solvent penetration is the slowest and, hence, is the rate-limiting step. However, when the water penetration rate is much lower then the polymer relaxation rate, the values of $n$ may be lower than 0.5 [36]. In most published reports on the hydrogel swelling, values of $n$ close to 0.5 or over 0.5 are presented. Only a few papers report values of $n<0.5$ [25, 43-47].

The swelling rates of the $\mathrm{Ch}, \mathrm{Ch} / \mathrm{GA}$ and $\mathrm{Ch} / \mathrm{GA} / \mathrm{SA}$ hydrogel membranes were described with Schott's second-order swelling kinetics [48]:

$\frac{d S}{d t}=k_{S}\left(S_{e q}-S\right)^{2}$

where $S_{\text {eq }}$ is the equilibrium water swelling ratio, $S$ is the water swelling ratio at time $t, k_{\mathrm{S}}$ is the swelling rate constant, respectively. After definite integration between the limits $S=0$ at $t=0$ and $S=\mathrm{S}$ at $t=t$ and rearrangement, Eq. (5) can be rewritten as follows:

$\frac{t}{S}=A+B t$ where $B=1 / S_{\text {eq }}$ is the reciprocal of the equilibrium swelling ratio and $A=1 / k_{\mathrm{S}} S_{\mathrm{eq}}^{2}$ is the reciprocal of the initial swelling rate of the hydrogel.

To test the kinetics model described above, $t / S$ vs. $t$ graphs were plotted for analysed hydrogel membranes and representative graphs are presented in Figs. 11 and 12. Values of swelling rate constant and equilibrium swelling ratio, which were calculated from the slope and the intersection of the lines, respectively, are presented in Table 2. In this table the experimental values of $S_{\mathrm{eq}}^{\mathrm{exp}}$ are listed for comparison. All determination coefficients $R^{2}$ are greater than 0.998 , indicating a small standard error and high precise linear regression equation. Values of the calculated equilibrium degree of swelling $S_{\text {eq }}^{\text {calc }}$ are in good agreement with the experimental data. These results suggest that Schott's second-order kinetic equation is adequate to describe the whole swelling process of chitosan hydrogel membranes in buffer solutions. Our results are consistent with the statements of others that the swelling kinetics behaviour of ionic hydrogels (anionic and cationic hydrogels) is in good accordance with Schott's second-order diffusion kinetics [49-55].

Table 2 shows that values of apparent swelling rate constant for $\mathrm{Ch} / \mathrm{GA}$ and $\mathrm{Ch} / \mathrm{GA} / \mathrm{SA}$ membranes are of the same order of magnitude for acidic and neutral swelling media but they increase for alkaline solutions. Thus, the swelling process of the cross-linked hydrogel membranes becomes somewhat faster at $\mathrm{pH}$ greater than 7 . The appreciable change of the swelling rate constant at certain $\mathrm{pH}$ was observed earlier by Guilherme et al. [41] for polymer networks structured on vinyl-functionalized pectin (hydrogels with carboxylic acid groups). These researchers reported an appreciable decrease of $k_{\mathrm{S}}$ for $\mathrm{pH}$ greater than 6 . Thus, both for chitosan hydrogel membranes (cationic hydrogels) and hydrogels based on vinyl-functionalized pectin (anionic hydrogels), the appreciable changes of $k_{\mathrm{S}}$ at certain $\mathrm{pH}$ could be associated with changes in degree of ionisation of the functional groups.

\section{Conclusions}

In this study chitosan was cross-linked with glutaraldehyde or with glutaraldehyde and sulfuric acid to obtain $\mathrm{pH}$-responsive membranes with improved stability in acidic media. The FTIR spectroscopy data confirmed the formation of covalent and ionic cross-links between chitosan and cross-linking agents. The WAXD studies indicated the effect of cross-linking on the chitosan membrane crystallinity. Chemical modification (cross-linking by GA or by GA and SA) led to a decrease of thermal stability of the chitosan membrane. No characteristic changes in morphology of the chitosan membrane were observed after its cross-linking. SEM images indicated that both non-cross-linked and cross-linked membranes exhibited dense structure without any pores. The cross-linking process caused 


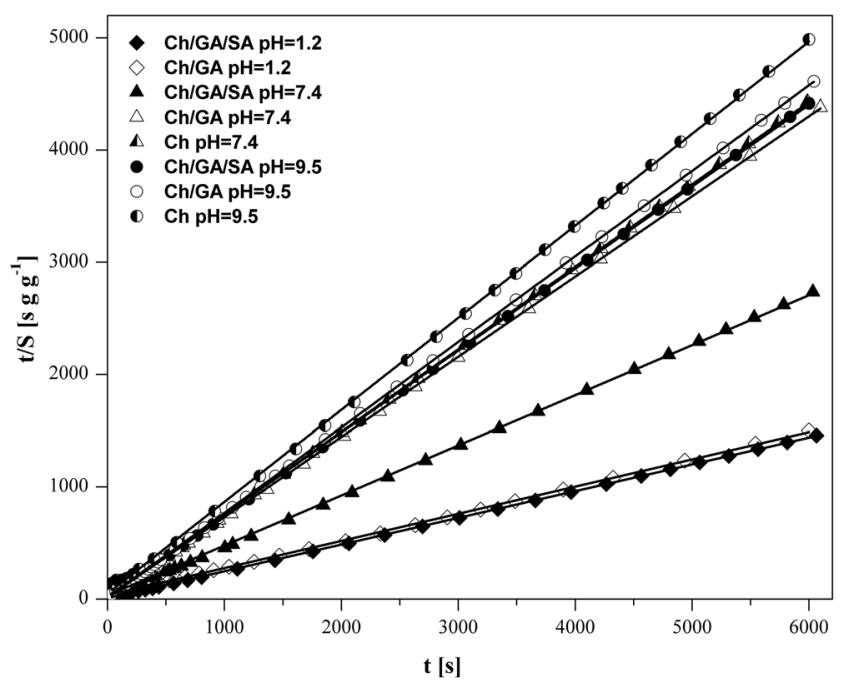

Fig. 11 Plots of $t / S$ versus $t$ for $\mathrm{Ch}, \mathrm{Ch} / \mathrm{GA}$ and $\mathrm{Ch} / \mathrm{GA} / \mathrm{SA}$ membranes in selected buffer solutions

a small increase of the surface roughness of the chitosan membrane.

The swelling behaviour of $\mathrm{Ch}, \mathrm{Ch} / \mathrm{GA}$ and $\mathrm{Ch} / \mathrm{GA} / \mathrm{SA}$ hydrogel membranes was studied in buffer solutions of different $\mathrm{pH}$. All the membranes exhibited a $\mathrm{pH}$-responsive swelling. $S_{\text {eq }}$ for cross-linked membranes in the acidic solutions was high and changed little with the $\mathrm{pH}$ of the buffer solution, but a sharp change of that value was observed in the $\mathrm{pH}$ range of 5-6 for $\mathrm{Ch} / \mathrm{GA}$ and in the $\mathrm{pH}$ range of $6-7$ for $\mathrm{Ch} / \mathrm{GA} / \mathrm{SA}$ membranes.

The mechanism of water transport through the hydrogel membranes was dependent both on the membrane type and the $\mathrm{pH}$ of the swelling medium. For all membranes, coefficient $n$ was dependent on the $\mathrm{pH}$ of the swelling medium. For non-cross-linked chitosan membrane, values of $n$ decreased with $\mathrm{pH}$ increase and ranged between 0.99 (for $\mathrm{pH}$ 7.4) and

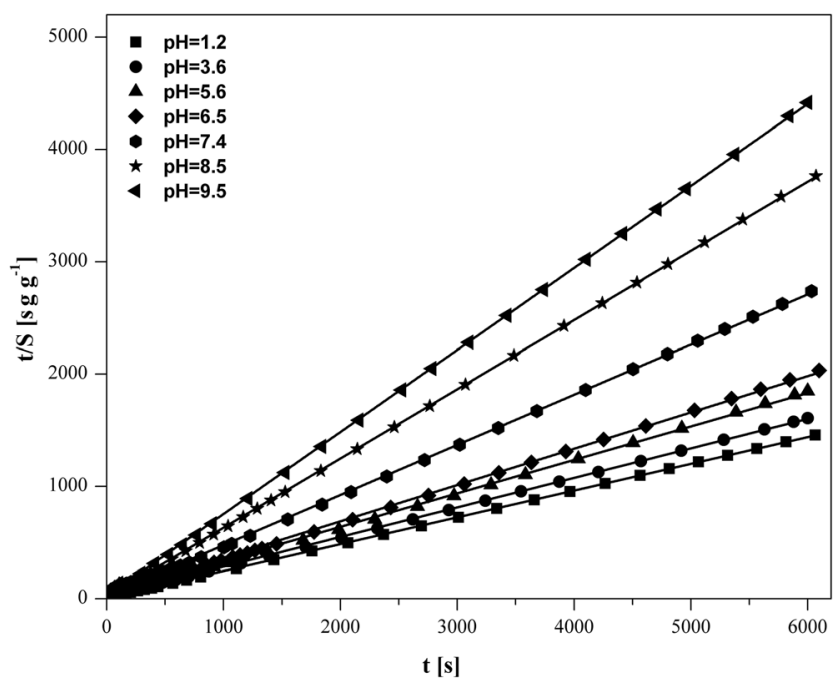

Fig. 12 Plots of $t / S$ versus $t$ for $\mathrm{Ch} / \mathrm{GA} / \mathrm{SA}$ membrane in all studied buffer solutions
0.85 (for $\mathrm{pH} 9.5$ ). Thus, $\mathrm{Ch}$ membrane showed a non-Fickian swelling behaviour in the studied buffer solutions. In the case of $\mathrm{Ch} / \mathrm{GA} / \mathrm{SA}$ membrane, values of $n$ are higher than 0.5 in buffer solutions of $\mathrm{pH}<6.5$, but they are close to 0.5 in solutions of $\mathrm{pH} \geq 6.5$. This indicates a shift of water transport mechanism from anomalous to Fickian type, i.e. from relaxation-controlled to diffusion-controlled. It can be supposed that the observed shift of water transport mechanism resulted from deprotonation of amine functional groups.

The experimental data indicated that the swelling process followed second-order kinetics for all the studied systems. The obtained values of apparent swelling rate constant for $\mathrm{Ch} / \mathrm{GA}$ and $\mathrm{Ch} / \mathrm{GA} / \mathrm{SA}$ membranes were of the same order of magnitude for acidic and neutral swelling media but they increased for alkaline solutions. Thus, the swelling process of the cross-linked hydrogel membranes became accelerated in alkaline media.

Open Access This article is distributed under the terms of the Creative Commons Attribution 4.0 International License (http:// creativecommons.org/licenses/by/4.0/), which permits unrestricted use, distribution, and reproduction in any medium, provided you give appropriate credit to the original author(s) and the source, provide a link to the Creative Commons license, and indicate if changes were made.

\section{References}

1. Wandera D, Wickramasinghe SR, Husson SM (2010) Stimuliresponsive membranes. J Membr Sci 357:6-35

2. Husson MS (2013) In: Bhattacharyya D, Schäfer T, Wickramasinghe SR, Daunert S (eds) Responsive membranes and materials. Wiley, Chichester

3. Zhao C, Nie S, Tang M, Sun S (2011) Polymeric pH-sensitive membranes - a review. Prog Polym Sci 36:1499-1520

4. Rinaudo M (2006) Chitin and chitosan: properties and applications. Prog Polym Sci 31:603-632

5. Uragami T (2011) In: Kim S-K (ed) Chitin, chitosan, oligosaccharides and their derivatives. CRC, Boca Raton

6. Ostrowska-Czubenko J, Pieróg M, Gierszewska-Drużyńska M (2013) Water state in chemically and physically crosslinked chitosan membranes. J Appl Polym Sci 130:1707-1715

7. Rao CNR (1963) Chemical application of infrared spectroscopy. Academic, New York

8. Pearson FG, Marchessault RH, Liang CY (1960) Infrared spectra of crystalline polysaccharides. V Chitin J Polym Sci 43:101-116

9. Knaul JZ, Hudson SM, Creber KAM (1999) Improved mechanical properties of chitosan fibres. J Appl Polym Sci 72:1721-1732

10. Ogawa K, Yui T (1993) Crystallinity of partially N-acetylated chitosan. Biosci Biotech Bioch 57:1466-1469

11. Neto CGT, Giacometti JA, Job AE, Ferreira FC, Fonseca JLC, Pereira MR (2005) Thermal analysis of chitosan networks. Carbohydr Polym 62:97-103

12. Nieto JM, Peniche-Covas C, Padron G (1991) Characterization of chitosan by pyrolysis-mass spectrometry, thermal analysis and differential scanning calorimetry. Thermochim Acta 176:63-68

13. Osifo PO, Masala A (2010) Characterization of direct methanol fuell cell (DMFC) applications with $\mathrm{H}_{2} \mathrm{SO}_{4}$ modified chitosan membrane. J Power Sources 195:4915-4922 
14. Zeng L, Qin C, Wang L, Li W (2011) Volatile compounds formed from the pyrolysis of chitosan. Carbohydr Polym 83:1553-1557

15. Yang JM, Su WY (2011) Preparation and characterization of chitosan hydrogel membrane for permeation of 5-fluorouracil. Mat Sci Eng C 31:1002-1009

16. Mukoma P, Jooste BR, Vosloo HCM (2004) Synthesis and characterization of cross-linked chitosan membranes for application as alternative proton exchange membrane materials in fuel cells. $\mathrm{J}$ Power Sources 136:16-23

17. Trimukhe KD, Varma AJ (2009) Metal complexes of crosslinked chitosans: correlations between metal ion complexation values and thermal properties. Carbohydr Polym 75:63-70

18. Kittur FS, Prashanth KVH, Sankar KU, Tharanathan RN (2002) Characterization of chitin, chitosan and their carboxymethyl derivatives by differential scanning calorimetry. Carbohydr Polym 49: $185-193$

19. Qu X, Wirsen A, Albertsson A-C (2000) Effect of lactic/glycolic acid side chains on the thermal degradation kinetics of chitosan derivatives. Polymer 41:4841-4847

20. Ge J, Cui Y, Yan Y, Jiang W (2000) The effect of structure on pervaporation of chitosan membrane. J Membrane Sci 165:75-81

21. Zhang XZ, Wu DQ, Chu CC (2003) Effect of the crosslinking level on the properties of temperature-sensitive poly (Nisopropylacrylamide) hydrogels. J Polym Sci Pol Phys 41:582-593

22. Peppas NA, Khare AR (1993) Preparation, structure and diffusional behaviour of hydrogels in controlled release. Adv Drug Deliver Rev 11:1-35

23. Peppas NA, Bures P, Leobandung W, Ichikawa H (2000) Hydrogels in pharmaceutical formulations. Eur J Pharm Biopharm 50:27-46

24. Berger J, Reist M, Mayer JM, Felt O, Peppas NA, Gurny R (2004) Structure and interactions in covalently and ionically crosslinked chitosan hydrogels for biomedical applications. Eur J Pharm Biopharm 57:19-34

25. Bajpai SK, Singh S (2006) Analysis of swelling behaviour of poly (methacrylamide-co-methacrylic acid) hydrogels and effect of synthesis conditions on water uptake. React Funct Polym 66:431-440

26. Mudassir J, Ranjha NM (2008) Dynamic and equilibrium swelling studies: crosslinked $\mathrm{pH}$ sensitive methyl methacrylate-co-itaconic acid (MMA-co-IA) hydrogels. J Polym Res 15:195-203

27. Domard A (1987) $\mathrm{pH}$ and c.d. measurements on a fully deacetylated chitosan. Int J Biol Macromol 9:98-104

28. Wang QZ, Chen XG, Liu N, Wang SX, Liu CS, Meng XH, Liu CG (2006) Protonation constants of chitosan with different molecular weight and degree of deacetylation. Carbohydr Polym 65:194-201

29. Khare AR, Peppas NA (1995) Swelling/deswelling of anionic copolymer gels. Biomaterials 16:559-567

30. Peppas NA, Franson NM (1983) The swelling interface number as a criterion for prediction of diffusional solute release mechanisms in swellable polymers. J Polym Sci Pol Phys 21:983-997

31. Ritger PL, Peppas NA (1987) A simple equation for description of solute release. II Fickian and anomalous release from swellable devices. J Control Release 5:37-42

32. Kim B, Flamme KL, Peppas NA (2003) Dynamic swelling behaviour of $\mathrm{pH}$-sensitive anionic hydrogels used for protein delivery. $\mathrm{J}$ Appl Polym Sci 89:1606-1613

33. Crank J (1970) Mathematics of diffusion. Oxford University Press, New York

34. Masaro L, Zhu XX (1999) Physical models of diffusion for polymer solutions, gels and solids. Prog Polym Sci 24:731-775

35. Ganji F, Vasheghani-Farahani S, Vasheghani-Farahani E (2010) Theoretical description of hydrogel swelling. A review. Iran Polym J 19:375-398

36. Karimi M (2011) In: Markos J (ed) Diffusion in polymer solids and solutions. Mass transfer in chemical engineering. InTech pp. 17-40 http://www.intechopen.com/books/mass-transfer-in-chemicalengineering-processes/diffusion-in-polymersolids-and-solutions

37. Peppas NA, Brannon-Peppas L (1994) Water diffusion and sorption in amorphous macromolecular systems and foods. J Food Eng 22: $189-210$

38. Alfrey TJ, Gurnee EF, Lloyd WG (1966) Diffusion in glassy polymers. J Polym Sci C 12:249-261

39. Thakur A, Wanchoo RK, Singh P (2011) Structural parameters and swelling behavior of $\mathrm{pH}$ sensitive poly (acrylamide-co-acrylic acid) hydrogels. Chem Biochem Eng Q 25:181-194

40. Krušić MK, Danković D, Nikolić M, Filipović J (2004) Poly(acrylamide-co-itaconic acid) and semi-IPNS with poly ethylene glycol). Preparation and characterization. Macromol Chem Phys 205:2214-2220

41. Guilherme MR, Moia TA, Reis AV, Paulino AT, Rubira AF, Mattoso LHC, Muniz EC, Tambourgi EB (2009) Synthesis and water absorption transport mechanism of a $\mathrm{pH}$-sensitive polymer network structured on vinyl-functionalized pectin. Biomacromolecules 10:190-196

42. Brannon-Peppas L, Peppas NA (1990) Dynamic and equilibrium swelling behaviour of $\mathrm{pH}$-sensitive hydrogels containing 2hydroxyethyl methacrylate. Biomaterials 11:635-644

43. Bajpai AK, Bajpai J, Shukla S (2001) Water sorption through a semi-interpenetrating polymer network (IPN) with hydrophilic and hydrophobic chains. React Funct Polym 50:9-21

44. Wang J, Wu W, Lin Z (2008) Kinetics and thermodynamics of the water sorption of 2-hydroxyethyl methacrylate/styrene copolymer hydrogels. J Appl Polym Sci 109:3018-3023

45. Özeroglu C, Birdal A (2009) Swelling properties of acrylamide-N, $\mathrm{N}^{\prime}$-methylene bis (acrylamide) hydrogels synthesized by using meso-2,3-dimercaptosuccinic acid-cerium (IV) redox couple. Express Polym Lett 3:168-176

46. Deen GR, Chua V, Ilyas U (2012) Synthesis, swelling properties, and network structure of new stimuli-responsive poly (N-acryloylN-ethyl piperazine-co-N-isopropylacrylamide) hydrogels. J Polym Sci Pol Chem 50:3363-3372

47. Bueno VB, Bentini R, Catalani LH, Petri DFS (2013) Synthesis and swelling behavior of xanthan-based hydrogels. Carbohydr Polym 92:1091-1099

48. Schott H (1992) Swelling kinetics of polymers. J Macromol Sci Phys 31:1-9

49. Yin Y, Yang Y, Xu H (2002) Hydrophobically modified hydrogels containing azoaromatic cross-links: swelling properties, degradation in vivo and application in drug delivery. Eur Polym J 38: 2305-2311

50. Diez-Pena E, Quijada-Garrido I, Barrales-Rienda JM (2002) Hydrogen-bonding effects on the dynamic swelling of $\mathrm{p}(\mathrm{N}-$ iPAAm-co-MAA) copolymers. A case of autocatalytic swelling kinetics. Macromolecules 35:8882-8888

51. Wei Q-B, Fu F, Zhang Y-Q, Tang L (2015) Synthesis and characterization of $\mathrm{pH}$-responsive carboxymethyl chitosan-g-polyacrylic acid hydrogels. J Polym Res 22:15

52. Krušić MK, Danković D, Nikolić M, Filipović J (2006) Copolymer hydrogels based on $\mathrm{N}$-isopropylacrylamide and itaconic acid. Polymer 47:148-155

53. Bamgbose JT, Bamigbade AA, Adewuyi S, Dare EO, Lasisi AA, Njah AN (2012) Equilibrium swelling and kinetic studies of highly swollen chitosan film. J Chem Chem Eng 6:272-283

54. Trivedi JH (2013) Synthesis, characterization and swelling behavior of superabsorbent hydrogel from sodium salt of partially carboxymethylated tamarind kernel powder-g-PAN. J Appl Polym Sci 129:1992-2003

55. Yin Y, Lv X, Tu H, Xu S, Zheng H (2010) Preparation and swelling kinetics of $\mathrm{pH}$-sensitive photocrosslinked hydrogel based on carboxymethyl chitosan. J Polym Res 17:471-479 